\title{
Obviating learning difficulties among Nigerian adult learners through andragogical instructional Delivery methods
}

\author{
Akpama, S.Ibor, Betiang, P .A, Akpama, Victoria \& Betiang, Elizabeth. \\ Department of Adult and Continuing Education Faculty of Education University of Calabar, Nigeria
}

\begin{abstract}
A plethora of scholars have recently associated the obvious deterioration in the academic achievements of adult learners with learning difficulties encountered in divergent learning settings. Similarly, abysmal performance in learning activities due to learning difficulties could inarguably culminate in aggravating the drop out syndrome with its attendant potentials for compounding the unabating and festering problem of illiteracy in Nigeria. Sadly, Nigeria has been fingered among the E-9 countries which harbour the highest number of illiterates globally.

In order to avert the plummeted observed downward trend in the academic achievement of adult learners, these learning difficulties must be identified and assuaged.

Indifference to these learning constraints of adults could undermine and scuttle current concerted efforts at attaining 50\% improvement in the levels of adult literacy by 2015 as enunciated in the education for All (EFA) global blue print. It is in view of this, that this paper discusses the issue of learning difficulties, its patterns and relevant andragogical instructional delivery techniques or methods for attenuating these learning constraints with a view to improving learning outcomes and thus complement the combat against the problem of increasing illiteracy rates in Nigeria.
\end{abstract}

\section{Introduction}

Until recently, the misjudgement that adults with learning difficulties have lost their basic intellectual functioning has been religiously upheld by numerous non-professionals and neophytes in the field of adult learning. This erroneous assumption undergirds the unwillingness of society and various government agencies to provide ample access to and congenial educational opportunities for such adults to actualize their academic and career aspirations. Corroborating this stand point, Sutcliffe, (1990) and Preece (2009) assert that adults with learning difficulties have been subjected to dehumanizing, contemptuous and distressing experiences. This situation has impeded their willingness to make more concerted efforts at improving themselves academically and thus extricate themselves from the poverties in which they are trapped (Preece, 2009). In order to reverse this negative attitudinal trend and facilitate adult learning, the difficulties adult learners encounter must be obviated and this forms the crux of this discourse.

\section{Concepts of learning and learning difficulties among adults}

Ekeruo, Ikediashi, Ekwe \& Nwanuo (1989) and Denga \& Akuto (2004) have defined learning as a relatively permanent change in behaviour as evidenced by a change in performance through practice, training or experience. It is also conceptualized as a process of making change in knowledge, skills, understandings, attitudes, and value systems and in behaviour (Rogers, 1989; \& Preece, 2009).

Essentially, for any observed behaviour to be perceived as learning the under listed characteristics must be exuded. There must be a behaviour change, which must not be synonyms with biological growth and maturation, disease or physical damage. Also, the behaviour change must be permanent and such behaviour change must emanate from different experiences (Ukpong, $2000 \&$ Biao and Tawo, 2007).

This implies that effective learning results in desirable changes in the individual and culminates in the development of society. Despite the utilitarian role of learning, it is not a rosy activity for all adults. Some adults experience few difficulties while others encounter numerous problems in their bid to participate in learning activities (Akpama, 2000).

Oduaran (2000) aptly describes adults with learning difficulties as adult learners with severe learning difficulties. According to this scholar, the spectrum of learning difficulties is divergent. It ranges from the mild or moderate learning difficulties to the severe or conspicuous and multiple learning difficulties. This broad categorization unfortunately undermines the fact that adults are in the first instance, individuals, who can maximally develop their potentials given the requisite opportunities.

According to Sutcliffe (1990:5) in several parts of the world it has been proven that adults with learning difficulties can be assisted to become useful to themselves and their respective societies. The United Kingdom's National Institute of Adult and Continuing Education (NICAE) Rowntree project or experiment set 
up in 1988 with the support of Joseph Rowntree Foundation substantiates the new and positive thinking about adults with learning difficulties.

Besides, the current participation in sports and giant strides made by disabled men and women world wide justifies the advocacy that adults will excel despite their disabilities if given ample opportunities in any field of human endeavour.

\section{Typical signs of learning difficulties}

Adults who manifest these symptoms are not necessarily sub-average in intelligence. They may be normal but still experience some unusual learning difficulties. These signs of learning difficulties as enumerated by Denga \& Akuto (2004:3) include: great difficulties in calculation generally, poor eye-hand coordination, short memory and poor reasoning, poor social competence, poor reading skills, poor communication skills because of poor language ability, low self esteem and so on.

\section{Kinds of learning difficulties}

There are different kinds of learning difficulties among which are the following:

\section{i. Cognitive difficulties}

These include reading inabilities or profound slow reading speed, acute problem or inability to comprehend or high rate of forgetting. Most of these cognitive difficulties are a function of lack of intelligence (Denga \& Akuto, 2004) and general intellectual decline in adulthood (Frozard \& Nuttal, 1971) cited in Ukpong (2000). According to Ukpong (2000) and Fasokun et al (2005) the speed hypothesis, the disuse hypothesis and the changing environment hypothesis provide evidence in support of decrease in cognitive performance with age. However, an improved learning environment helps to attenuate these problems.

\section{ii. Social learning difficulties}

It must be established that both social learning and cognitive learning are complementary. Social competence and mental competence interact (Denga, et al 2004). Oduaran (2000) defines social learning inability as the individual's low self concept or unwillingness to socialize. Adults who are shy and withdrawn seldom ask and answer questions in class. The tendency further retards their intellectual functioning. They are lonesome, emotional and in some cases excessively aggressive or hostile. Group learning thus becomes difficult for such adults since they cannot easily conform to a corporate or group standard of behaviour.

Oduaran (2000:84-85) listed other typical learning difficulties to include:

$>$ Clinical mental inability to really learn bordering on psychiatric problems

$>$ Adults with cerebral palsy, affecting their mobility and co-ordination.

$>$ Adults with communication problem resulting from speech or visual or hearing impairment, which affects their communication skills

> Adults having other physical disabilities, which reduce their ability to get around and avail themselves of the opportunities to learn.

Most of the difficulties highlighted above minimize the degree of enthusiastic participation of adults in learning and are responsible for isolation of those who fall into the categories of people provided with "special schools", separate transport (or special buses or ambulances or excavators), long-stay in hospitals, large hostels, isolated day centres, and special clubs among others (Oduaran, 2000:85).

Similarly, Max (1992) listed typical obstacles to learning to include inadequate transportation, time limitations, high costs, low self-esteem, or self confidence, stereotypes regarding the elderly and education, and lack of knowledge, about various learning opportunities, health related limitations and overall health status such as fatigue, reduced mobility and declining hearing or visual acuity can also impact on learning ability and activity.

\section{Possible sources of learning difficulties}

Numerous factors underlie learning difficulties which are inextricably linked with the under mentioned sources.

\section{i. Genetic sources}

Intelligence, which encompasses the general ability to learn, is partly genetically determined. In other words heredity plays a critical role in the intellectual development of any individual. Denga \& Akuto (2004) state that some learning difficulties of learners (children and adults) apart from the factors of interest, age and teaching methods can be traced to either one parent or both parents through the contribution of genes at the stage of conception.

\section{ii Environmental sources}


Apart from the exponents who believe that intelligence is inherited or innate, Ukpong (2000) observes that even though there is a ceiling that cannot be exceeded, positive and enriched experiences can improve intellectual functioning within the limits fixed by heredity. Fisher (1973) also states that individuals may have high or low potentials for the development of certain skills or personality traits but it is only the combination of a high potential and the best environmental influence that will guarantee maximum intellectual development. This means that intelligence is attributed to an interplay of both heredity and environment.

Within this context, environment implies the physical, physiological, psychological and social circumstances surrounding the adult learner. Oduaran (2000) describes theses factors as situational factors which could impede learning and which include among others, an unconducive learning environment. The learning environment could be too hot, or too cold, too stuffy, overcrowded, poorly equipped, with poor toilet facilities; or lack of seats, or lack of good seats, or other numerous distractions among others.

\section{iii. Poor instructional methods}

Oduaran (2000) states that there are facilitators who are unable to communicate with the adult learners or those who will not accept any excuses. This constitutes poor relationship between the facilitator and the learner. Non professionals and neophytes who do not use appropriate instructional methods compound the problems of adult learners. This implies that inappropriate choice of methods results in creating learning difficulties for the learner.

However, Rogers (1986:144) established the basis for the choice of methods. According to him, the following considerations should guide the facilitator in selecting instructional methods.

$>$ The areas(s) of learning at a given time, (example is it skills, knowledge, understanding, or attitude).

$>$ The active participation of the learners

$>$ The learners' preferred learning styles

$>$ The subject matter's demands or exigencies.

$>$ The amount of resources available

It must be noted that poor instructional methods exacerbated by shallow understanding of the concepts or skills being taught multiply the learning difficulties of adult learners. Therefore, experienced adult educators must use appropriate presentation techniques such as demonstration, exposition, interaction (example questions and answers, role-play, discussion, buzz groups) and exploratory (example individual project, assignments, practice, experiments etc) (Oduaran, 2000:111).

\section{iv. Health sources}

Ukpong (2000) and Biao \& Tawo (2007) state that in adulthood there is a gradual change in some biological processes-even in the absence of disease. However, the effect of aging on physical health cannot be disputed. Portman and Alexander (1972) indicate a high correlation between aging and diseases, each of which compound the other. Adult learners' performance is affected by the physical and health conditions of the person as well as the social conditions within which he lives and functions. Apart from other organs, some age related changes occur in the sensory modalities such as reduced vision, and hearing which create some learning difficulties for adult learners.

\section{v. Interest as a source of learning difficulty}

Adults actively and enthusiastically participate in learning activities which are of interest and immediate relevance to them. This implies that if adults are subjected to acquire knowledge and skills, which are not of immediate relevance to them, their interest in the learning activity would diminish and this will create problems (Anyanwu, 1981), in essence learning which involves adults must be learner-centred to motivate them and minimize learning difficulties. (Nzeneri, 2008).

\section{Inadequate instructional materials}

Appropriate and adequate instructional materials enhance effective adult learning. On the other hand acute shortage of such devices such as instructional materials create learning difficulties. Oduaran (2000) listed among others such devices as Audio-aids, example radio, cassette, recorders etc; Visuals example films, filmstrips, pictures, maps, paintings, drawings, flip charts, chalk boards, mobiles, stabiles etc and audio/visual aids which refer to those devices combining the sense of hearing and seeing example the television, video etc.

These instructional materials are vital to effectuate adult learning given the factor of acute physiological defects, which hamper effective adult learning, especially in the absence of such learning facilitating devices.

\section{Coping strategies}


The kernel of this component of the discussion is to elucidate coping strategies which will enhance effective learning despite the difficulties adult learners encounter. Sutcliffe (1990) asserts that among the coping strategies for reversing the trend of inhuman treatment of adults with learning difficulties include:

i. Normalization: Normalization is a new approach for attenuating the problems of adults with learning difficulties so that they can become more successful in life and positively valued by others in their society. Therefore, normalization has been useful in getting adults with learning difficulties to speak up for themselves and debunk such previous stigmas as "uneducable", educationally subnormal" or mentally handicapped.

According to Oduaran (2000) normalization has made available a set of values, which help adults to reverse negative factors. Sutcliffe (1990:8-9) in Oduaran (2000:86) provides a list of dehumanizing experiences in list $\mathrm{A}$ and $\mathrm{B}$ complementary range of experiences mediated by normalization in list $\mathrm{B}$ as follows:

\begin{tabular}{|l|l|}
\hline List A & List B \\
\hline (Dehumanizing experiences) & Normalization experiences) \\
\hline Segregation from others & Opportunities for integration \\
\hline Low expectations of achievement & High expectation for development \\
\hline Lack of choice & Provision of individual choice \\
\hline Being treated childishly & Being treated as an adult and equal \\
\hline Denial of rights and dignity & Conferring rights, respect and dignity \\
\hline
\end{tabular}

Source: Sutcliffe 1990:8-9 cited in Oduaran (2000:86)

Based on the above normalization arrangement an array of services are made available to adults with learning difficulties which could enable many of them to engage in "self advocacy". Self advocacy means the process whereby people with learning difficulties articulate their problems, "speak up" or speak out" for themselves.

ii. Identification of target group: The second strategy is to accurately identify adults with learning difficulties and their different settings.

iii. Advocacy: Self-advocacy must be promoted since it enhances individual change.

The values of self-advocacy require that the professionals organize learning in a framework, which helps those adults with learning difficulties to "speak up" and speak out for themselves. These adults must be helped to recognize life stories and experiences, which are built around them. Self-advocacy can be woven round ethnic groups, individuals, and independent groups of people with similar problems, people who have been institutionalized and projected to serve as tutors and planners as well (Oduaran, 2000:87).

iv. Identify and implement learning choices

In spite of their learning difficulties, adult learners have choices as to what they wish to learn. Therefore care must be taken to identify and provide the choices as a way of enriching their education. This must be done with the full and active participation of the adults themselves. The adults with these problems must be involved fully in what they want to learn and in deciding whether they want to learn at all. The Rowntree project set up in 1988 on which Sutcliffe (1990:36) reported indicates that:

$>$ Adults are in education classes for the reason that attending will be good for them.

$>$ The same day centre students are in college each year because their names are on the list of those expected to attend.

$>$ Adults from local day centres are enlisted to learn engineering because the lecturer has space for them.

$>$ Large groups of residents in one hospital are sent to evening classes enbloc.

A cursory examination of Sutcliffe's projections listed above shows unfortunately that arrangements for the participation of adults with learning difficulties in the process of learning are generally not sensitive and responsive to their interests, needs and motivation. Most provisions are structured for the convenience of staff, which is unethical, restrictive and unstimulating. In light of this, Oduaran (2000:88) listed the following other learning enhancing strategies for adults with learning difficulties.

$>$ Open up new opportunities for the learners

$>$ Provide access to information about learning opportunities in the locality

$>$ Provide them effective educational guidance and counselling 
Promote adult learners' ability to make informed decisions about what to learn by exposing them to taster sessions (at taster sessions adults are provided with a sample of subjects in one day or two so that they can see what it involves).

\section{v. Involve learners in planning their learning}

The activities involved are:

$>$ Stating the aims and objectives for learning with the full participation of the adult learners.

$>$ Applying assessment to the process of finding out where to start.

$>$ Determining learning styles, models and materials

$>$ Executing of the plan for teaching the learners.

$>$ Evaluation of the outcomes of learning in order to discover whether or not the aims and objectives have been achieved.

$>$ Deciding on what further actions should be taken in order to improve on present level of achievement

\section{vi. Establishing purposes of learning}

The commonest purposes of learning include:

$>$ Learning for employment or work

$>$ Learning for leisure and recreation

$>$ Learning for independence (the need to develop ways and means of overcoming personal difficulties)

$>$ Learning about how to maintain good relationships

$>$ Learning for personal improvement or self fulfilment

$>$ Learning for community service and so on.

\section{vii. Integration}

Integration is indispensable for adults with learning difficulties. It refers to the sharing of ordinary places and activities with other people. People with learning difficulties should not be stigmatized or and excluded from everyday life as a result of their disabilities. This would compound the physical and psychological pains associated with isolation and thereby perpetuate the myth that people need to be kept separate" (Sutcliffe, 1992:0-30; 190:90) cited in Oduaran, 2000:90). Therefore, such adults should be afforded opportunities to join activities along-side other people.

\section{Coping strategies for adults with profound complications}

For this special class, learning must be structured in such a manner to take care of the factors, which complicate their effective participation. The best approach to teach such adults, with profound and multiple learning difficulties is what Oduaran (2000) describes as quality individual work. In other words specialists should be consulted like speech therapists to cater for adults who must acquire skills in the area of language and communication. Adults with complications related to blindness and deafness should be referred to appropriate specialists while resources are made available for them to benefit from relevant adult education programmes. There are some who have challenging behaviour who would need services in behaviour modification or alternative skills development, counselling and psychotherapy, relaxing sessions, (employing Yoga, Music, massages, aromatherapy and breathing exercise) employment, life story work, interactive teaching and nonaversive teaching styles (Oduaran, 2000:91; Biao \& Tawo, 2007).

\section{Andragogical Assumptions}

Oduaran (2000) and Nzeneri (2008) assert that since adults unlike children attend classes and participate in programmes voluntarily, andragogical rather than pedagogical methods should be utilized to teach adults. Knowles (1970:53) defines andragogy as the art and science of helping adults learn. Andragogy is premised on four major assumptions which include:

i. $\quad$ Changes in self concept: This assumption implies that as a person grows and matures his selfconcept moves from one of total dependency to one of increasing self-directedness.

ii. The role of experience: The second assumption states that as an individual matures he accumulates an expanding reservoir of experience that causes him to become an increasingly rich resource for learning and which simultaneously provides him with a broadening base to which he can relate new learning.

iii. Readiness to learn: This assumption presupposes that as an individual matures his readiness to learn is decreasingly the product of his biological development and increasingly the product of the developmental tasks which are requisites for the performance of his evolving social oriented roles. 
iv. Orientation to learn: This assumption is that children have been conditioned to have a subject centred orientation to most learning. This position contradicts the orientation of adults to learning which is basically problem centred for immediate application of knowledge (Knowles, 1978:55-59 \& Nzeneri, 2008:138-139).

Instructional delivery methods which anchor on the afore listed principles could cushion various learning difficulties encountered by adult learners since it is dysfunctional to adopt teaching methods which are not adragogical in orientation. Knowles (1971) cited in Nzeneri (2008:138) aptly why adult education has not achieved the impact on civilization of which it is capable is that most teachers of adults have only known how to teach adults as of they were children.

This excerpt highlights a major source of learning difficulties which is utilization of pedagogical rather than andragogical instructional delivery techniques. Patricia Cross (1981:224) suggested a table which summarizes these basic differences which is presented in Table 1.

Table 1

Differences between pedagogy and andragogy

\begin{tabular}{|l|l|l|l|l|l|}
\hline Assumptions & & & & Design elements & Andragogy \\
\hline Self concept & Pedagogy & Dependency & $\begin{array}{l}\text { Increasing self } \\
\text { directedness }\end{array}$ & $\begin{array}{l}\text { Authority oriented } \\
\text { formal } \\
\text { competition }\end{array}$ & $\begin{array}{l}\text { Mutually respectful, } \\
\text { collaborative, } \\
\text { informal }\end{array}$ \\
\hline Experience & Of little worth & $\begin{array}{l}\text { Learners are a rich } \\
\text { resource for learning }\end{array}$ & $\begin{array}{l}\text { Planning teacher } \\
\text { mechanism for } \\
\text { mutual planning }\end{array}$ & By teacher \\
\hline Readiness & $\begin{array}{l}\text { Biological } \\
\text { development, social } \\
\text { pressure }\end{array}$ & $\begin{array}{l}\text { Developmental task of } \\
\text { social roles }\end{array}$ & $\begin{array}{l}\text { Diagnosis of } \\
\text { needs }\end{array}$ & By teacher \\
\hline Time perspective & $\begin{array}{l}\text { Postponed } \\
\text { application }\end{array}$ & $\begin{array}{l}\text { Immediacy of } \\
\text { application }\end{array}$ & $\begin{array}{l}\text { Formulation of } \\
\text { objectives }\end{array}$ & By teacher \\
\hline Orientation & Subject centred & Problem centred & Design & $\begin{array}{l}\text { Logic of subject } \\
\text { matter content } \\
\text { unit. }\end{array}$ & $\begin{array}{l}\text { Sequenced in terms } \\
\text { of reading problem } \\
\text { units. }\end{array}$ \\
\hline $\begin{array}{l}\text { Learning } \\
\text { activities }\end{array}$ & & $\begin{array}{l}\text { Transmittal } \\
\text { techniques }\end{array}$ & $\begin{array}{l}\text { Experimental } \\
\text { techniques (inquiry) }\end{array}$ \\
\hline & & Activities & $\begin{array}{l}\text { Mutual rediagnosis of } \\
\text { needs, mutual } \\
\text { measurement of } \\
\text { programme }\end{array}$ \\
\hline
\end{tabular}

Source: Patricia Cross (1981:224)

\section{Andragogical instructional delivery techniques}

In order to assuage the learning difficulties discussed in this paper, the underlisted instructional techniques are also suggested: cooperative learning, Brain storming, problem solving, role play, simulations, group discussions, case studies and dialogues among others.

Cooperative learning: Fasokun et al (2008) describe cooperation as working together to accomplish shared goals. Cooperative learning makes it possible for various small group interactive educational procedures to enable learners help themselves and their colleagues whose learning difficulties could be assuaged in this group setting.

Brainstorming: In brainstorming, learners come together to generate new ideas around a specific area of interest or difficulty. Brainstorming could help adult learners resolve some problems which hamper their learning activities.

Problem solving: Facilitators could use this method to motivate learners to apply their knowledge and experiences in solving the kinds of problems they are likely to encounter in life and work situations using small groups. Instructors could encourage learners to follow a systematic process involving problem identification, formulation of objectives, preparation of data collection instruments, collection and data analysis, producing results, drawing conclusions and making recommendations (Fasokun et al 2005).

Role play: Role play is the spontenous acting out of an incident by several members of a group (Galbraith \& Zelenak, 1991).

Role play, drama and story telling are preferred choices for adult learners (UNESCO, 2001). Role play helps learners to experience an issue directly; however, it must follow defined steps to achieve its purpose. These steps include choice of a subject matter and outline of a plot, use of flash cards, encouraging actors to be innovative, and arrangement of some time after the role play to discuss the experience. 
Simulations: In simulations, learners act out real life situations and values. Galbraith (1991) corroborates this view and assert that simulations entail setting up situations that approximate reality and then letting learners act out the situations.

Group discussions: Discussion is the core of learning activity when higher order learning out come such as critical thinking are valued (Garrison \& Archer 2000). Group discussion could be used to enhance learning since adult learners participate cooperatively with others. Learners with difficulties have the opportunities to discuss their problems through sharing of such information, knowledge and relevant ideas. Learners acquire new ideas to help resolve their learning difficulties through such group interactions.

Case studies: The case study offers learners another ample opportunity to analyse and resolve realistic dilemma or problems which they encounter in the teaching learning setting, work situations or daily life. Case studies help learners to define problems, explain issues, gather relevant data on problems, analyse data, interpret and discuss issues.

Dialogue: Dialogue facilitates learning among adults since learners have opportunities to challenge existing ideas or knowledge constructed by others. It serves as a parameter for assessing knowledge claims. Dialogue helps learners to resolve difficulties since it entails interplay of presenting, questioning, responding, reacting and structuring information and knowledge. These techniques when properly applied could help adult learners with difficulties to improve their academic work.

\section{Conclusion}

The paper surveyed the issue of obviating learning difficulties by employing relevant andragogical methods. Different sources of learning difficulties such as genetic sources, environmental, use of poor instructional methods and materials, health sources and interest related sources were identified. Types of learning difficulties such as cognitive difficulties, social learning difficulties, clinical mental inability, speech, visual, hearing and physical impairment related difficulties were discussed.

Coping strategies were identified and androgogical instructional delivery techniques such as brainstorming, problem solving, role play, simulations, group discussions, case studies and dialogues were highlighted as measures for attenuating learning difficulties encountered by adults in divergent learning settings.

\section{References}

[1]. Anyanwu, C.N. (1981) Principles and Practice of Adult Education and Community Development. Ibadan: Abi Print Publishing Company.

[2]. Akpama, S.I. (2000) Counseling strategies for enhancing adult learning. West African Journal of Educational Research 3, 1, $30-36$.

[3]. Biao, I. \& Tawo, R.E. (2007) Psychological principles of Adult Education. Calabar: Wusen Publishers.

[4]. Biao, I., Akpama, S.I., Tawo, R. \& Okukpon, L. (2009) Case study of two non-formal programmes in Cross River State, Nigeria. In Preece, J. (Ed), Non-formal education poverty reduction and life enhancement: A comparative study, Botswana: Lightbooks.

[5]. Delahaye, B.L. \& Smith, B.J. (1998) How to be an effective trainer. New York: Wiley.

[6]. Delahaye, B.L. (2000). Human resources development principles and practice. New York: John Wiley and Sons Australia Limited

[7]. Denga, D.I. \& Akuto, G.W. (2004) Learning difficulties and behaviour disorders among Nigerian children: with a glimpse at abnormal psychology. Calabar: Rapid Educational Publishers Limited

[8]. Donaldson, L. \& Scannel, E.E. (1986) Human resource development: The new trainers guide, (2 ${ }^{\text {nd }}$ Ed), Reading MA: AddisonWesley.

[9]. Ekervo, Ikediashi, Ekwe \& Nwamuo (1989) Essentials of educational psychology. Agbor: Central Book Limited

[10]. Fasokun, T. Katahorie A., Oduaran, A. (2005). African perspective on adult learning: The psychology of adult learning in African South Africa: Pearson Education and UNESCO.

[11]. Fisher, J. (1973) Competence, effective intellectual functioning and aging. The Gerontologies, 13, $62-68$.

[12]. Galbraith, M.W. \& Zelenak, (1991). Adult learning methods and techniques. In facilitating adult learning: A transactional process Ed. M.W. Galbraith pp. 103-133. Malabar, FL:Krieper Publishing Company.

[13]. Galbarith, M.W. Ed (1991). Facilitating adult learning. A transactional process. Malabar, FL: Krieger Publishing Company.

[14]. Harris, D. M. \& Desmione, R.L. (1994). Human resource development. Fort worth: Harcourt Brace.

[15]. James, W.B. \& Galbraith, M.U. (1984). Perceptional learning styles; implications and techniques for practitioners. Lifelong Learning, 7, (10), 20-23.

[16]. Jerry, W. Gilley \& Steven, A.E. (1989) Principles of Human Resource Development. Lincoln: Addison - Wesley Publishing Company Inc.

[17]. knox, A.B. (1986). How adults learn. A guide to planning, implementing and conducting programmes. San Francisco Jossey- Bass Publishers.

[18]. Knowles, M. (1978). The adult learner: A neglected species: second education, London: Guilt Publishing Company.

[19]. Knowles, M.S. (1970). The modern practice of adult education. Andragogy versus pedagogy. New Y ork: Association Press.

[20]. McGee, W. \& Thayer, P.W. (1961). Training in business and industry. New York. Wiley.

[21]. Miller, G.A. (1956). The magical number seven plus or minus two: some limits on our capacity for processing information. Psychological Review 63, 81-97.

[22]. Max, Vander Kamp (1992). Effective Adult learning in Albert Tuijnman and Max Vander Kamp (Eds). Learning across the lifespan, Theories, and Research policies. New York: Pergamon Press.

[23]. Nzeneri, I.S. (2008). Hand book on adult education: Principles and practice: New Edition. Uyo: Abigab Associates Limited.

[24]. Oduaran, A.B. (2000) Effective adult learning and teaching. Ibadan: Ibadan University Press.

[25]. Portman, O.W. \& Alexander, M. (1972). Changes in Arterial subtraction with aging and Atherosclerosis. Biochem Biophysics Acta 260 . 
[26]. Preece, J.L. (2009). Combating literacy with vocational skills: Two case studies of non-formal education for herd boys and farmers in Lesotho. In Preece, J. (Ed) Non formal education and poverty reduction and life enhancement: A comparative study. Botswana: Light-books.

[27]. Rogers, J. (1989). Adult Learning. Milton Keyness: Open University Press.

[28]. Sutcliffe, J. (1990). Adults with learning difficulties: Education for choice and empowerment. Leicester. The National Institute of Adult and Continuing Education and Buckingham: The Open University Press.

[29]. Sutcliffe, J. (1992). Integration for Adults with learning difficulties: contexts and debates. Leicester: The National Institute of Adult Education and Buckingham: The Open University Press.

[30]. Thorndike, E.L. (1913). The Psychology of Learning. New York: Macmillan.

[31]. Ukpong, E. (2000) The Psychology of Adult Learning Port Harcourt: Double Diamond Publications.

[32]. UNESCO (2001). Hand book: Non-formal adult education facilitators. Bangoke: UNESCO principal regional office for Asia and the pacific. 